assessment sheet has successfully helped in previous mock examinations.

The pre-planned assessment sheet has found a use for itself outside the examination scenario. Senior colleagues have taken to using it routinely in their out-patient clinics. It lends itself ideally to preparation of the clinical formulation of in-patients as advised in a respected pamphlet on clinical recording (Institute of Psychiatry and Maudsley Hospital, 1987). If it is of A4 size, it fits neatly into most hospital record files. The detailed format could easily be adapted to suit local needs. The small space allocated to the physical examination (meant simply to record positive findings in an examination setting) may not be sufficient for a head injured or severely physically handicapped patient.

The pre-planned assessment sheet cannot claim to confer a statistically proven advantage in the MRCPsych examination. Nevertheless, of the rela- tively small number of trainees who have included it as part of their examination technique, all reported on it favourably and all so far have been successful in their respective attempts at Part I and II of the MRCPsych. I therefore feel that it is now appropriate to suggest its use to a wider audience.

\section{References}

Holden, N. L. (1987) Examination Techniques in Psychiatry. London: Hodder \& Stoughton.

Institute OF Psychiatry and the MAUDSLEY Hospital (1987) Notes on Eliciting and Recording Clinical Information in Psychiatric Patients. Oxford: Oxford Medical Publications.

Pfefrer, J. M. \& Waldron, G. (1987) Psychiatric Differential Diagnosis. London: Churchill Livingstone.

Royal College of Psychiatrists (1987) Handbook for Inceptors and Trainees in Psychiatry. London: Royal College of Psychiatrists.

\title{
Conference reports
}

\section{Community care or community neglect?}

\author{
Rosalind Ramsay, Registrar in Psychiatry, University College and Middlesex School of \\ Medicine, London W1N 8AA
}

Junior Health Minister Roger Freeman faced a critical audience at the National Schizophrenia Fellowship Conference held on 6 December 1989. Mr Freeman has been keen to demonstrate his concern over the welfare of the mentally ill and their carers. In a provisional statement made in July he pledged support to ensure adequate care would be provided for all psychiatric patients before discharge from hospital into the community. The government's White Paper on Community Care (1989) sets out plans to develop locally based hospital and community services. At the NSF conference Mr Freeman reaffirmed support for this more 'civilised and humanitarian' policy.

$\mathrm{Mr}$ Freeman raised a number of issues in relation to the White Paper. He commented on the current lack of knowledge about the causes of mental illness, forcing doctors to take a pragmatic approach in developing new treatment strategies. He believed the need for hospital care, both on acute admission wards and in asylums for longer term management would continue, but at the same time he saw that greater opportunity for care in the community was essential. He also discussed the proposed care programme approach due to be launched in October 1991. This will require all psychiatric patients to be individually assessed for their health and social needs, so that realistic discharge plans can be drawn up involving available community facilities where possible before an individual leaves hospital. By managing resources at a local level, service planners will be able to determine the priorities of their own areas. Mr Freeman admitted the provisional nature of the plans. However, he hopes to work in close co-operation with statutory and voluntary services enabling modification of the new developments as necessary.

Mr Freeman's picture of future achievements did 
not satisfy all the delegates. Several relatives of mentally ill people expressed their frustration at the inability of hospital staff to accept responsibility for providing for the needs of a sick family member. These carers wanted more help now, not just a promise of improvements in the future.

Judy Weleminsky, Director of the NSF, pointed to the lack of detail in the government's proposals. Looking back to the formation of the NSF in 1971, families of the mentally ill then were desperate for more support and information. Services available for care of psychiatric patients have since deteriorated: the number of hospital beds has halved, yet less than one in ten has been replaced by equivalent community care facilities. Family members confronting 'community neglect' feel anguish and neglect. Mrs Weleminsky conceded that although there was much wrong with the old style mental hospitals, such institutions did offer a home, support and treatment for patients. Today if hospital admission occurs it is often too late and too short.

Mrs Weleminsky expressed some particular concerns over the White Paper, questioning the government's commitment to the mentally ill and whether it would show action to meet its words. Previously Roy Griffiths emphasised the importance of having clear direct responsibility within the Health Service; abdication of such responsibility fails the mentally ill. Mrs Weleminsky would like to see a national plan and a Minister for Community Care to avoid the growth of haphazard and patchy services. She particularly encouraged health planners to listen more to sufferers and carers and to try and engage them in their discussions. More specifically, she discussed the issue of resources. Based on Professor Julian Leff's research (TAPS, 1990) and using a lower estimate of say $£ 10,000$ per year to provide a minimum level of support out of hospital for one person, by 1991 the government could be spending at least $£ 250$ million on care of the mentally ill in the community. Dr James Birley, President of the College, emphasised the scale of planning necessary. Directors of health and social services would have to get together and make joint plans on how best to meet the needs of their local populations so that individual patients get optimum care. For any one patient the health and social care required are indivisible and it is our responsibility to develop facilities to meet those needs. Such moves demand extensive research for, "How can anyone devise community care plans for the future when we do not know how many people will need that care and what kind of care that should be?" (Wallace, 1989).

\section{References}

Department of Health (1989) Caring for People: Community Care in the Next Decade and Beyond. Cmd 849. London: HMSO.

Proceedings from the Fourth Annual Conference of the Team for the Assessment of Psychiatric Services (TAPS), held at St Bartholomew's Hospital Medical College, July 1989. London: NETRHA (in press).

WALlace, M. (1989) Mental Health Organisations express concern at White Paper on Community Care. News release, 16 November 1989.

\title{
Computers in Psychiatry Special Interest Group - 2nd Annual General Meeting
}

\author{
StePhen Wood, Consultant Psychiatrist and Senior Lecturer; and Michael Sinclair, \\ Research Psychologist, Mental Health Advice Centre, 1 Southbrook Road, \\ London SE12 8LH
}

If three psychiatrists are needed to change a light bulb - one to change the bulb and two to interpret the experience - how many does it need to operate a computer? Judging by the attendance at the 1989 CIPG meeting, held at Keele University in October, the answer is about 54 .

Psychiatrists have been slow off the mark to explore and exploit computer applications, partly because of the nature of their craft which does not readily lend itself to the limitations imposed by simple algorithms, but also because psychiatrists by their nature and training are probably the least technologically minded members of the medical profession. However there are exceptions to every rule, and many of them gathered at Keele to share their knowledge and exchange ideas. The participants 